\title{
VERY HIGH VOLUME GaAs MMICs
}

\author{
Christopher M. Snowden \\ Filtronic plc., \\ The Waterfront, Salts Mill Road, \\ Shipley. BD18 3TT. UK. csnowden@ filct.com
}

\begin{abstract}
The increase in demand for high performance semiconductor devices to supply the mobile communications market has led to dramatic developments in the compound semiconductor business, with the launch of a number of 6" GaAs foundries. The background to the demand for very high volumes of RF products for this market is discussed, together with the prospects for future growth. The recent establishment of a very large 6" GaAs facility by Filtronic plc in the UK is described together with the technical and economic considerations that will lead to a capacity of up to 175,000 wafers/annum.
\end{abstract}

\section{INTRODUCTION}

The dramatic increase in the use of mobile communications has led to a major shift in the usage of semiconductor products. It has been claimed that over the next few years, more cell phones and handheld devices will be linked to the Internet, than PC's. Operators are focused on delivering wireless access and services to users as soon as possible and OEMs have already demonstrated new designs of cell phones and accessories, including modules, which can add wireless connectivity to regular household appliances and industrial machinery. Whilst the market penetration for mobile phones is very high in several European countries, the major markets in the USA and China are growing rapidly from a lower base. Recent estimates of wireless data penetration have risen from 25 percent of U.S. cell-phone subscribers to 50 percent by 2007. OEMs are also addressing the automotive market and there are claims that all new cars would by the end of 2005 have at least one Internet address. It is predicted that the number of data-ready cell phone handsets would grow from more than 400 million this year to over 550 million in 2001 .

\section{THE GROWING GaAs SEMICONDUCTOR MARKET}

The market for GaAs products is expected to grow by over 30\% over the next 12 months, Figure 1. The most important market sector is represented by the wireless communications business as already outlined above, Figure 2. The total market for GaAs MMICs is expected to grow to over $\$ 3$ bn by 2003 [1]. The growth in the GaAs RF semiconductor business can be attributed to four key aspects. A major driver is the boom in the cellular market with unprecedented demand for handsets. The superior power added efficiency of GaAs power amplifiers together with their excellent linearity; low loss multi-way RF switches, and very low noise amplifiers has led to increasing use of these MMICs in new handset designs. Looking forward over the next three years, analysts expect the market for GaAs products in handsets to double by 2003 creating a total market value of over $\$ 1.5$ bn [1]. Secondly, the growth in cellular infrastructure (base-station) business and the move to new standards requiring higher linearity and better receiver sensitivity has led to increased demand for GaAs products. Additionally, the accelerating demand for broadband communication equipment to service the point-to-point, point-to-multipoint and emerging LMDS markets has stimulated 
further growth in the GaAs MMIC business. Finally, there remains a tremendous surge in demand for digital GaAs IC technology in wireline and optoelectronic applications.

GaAs Revenue Forecast

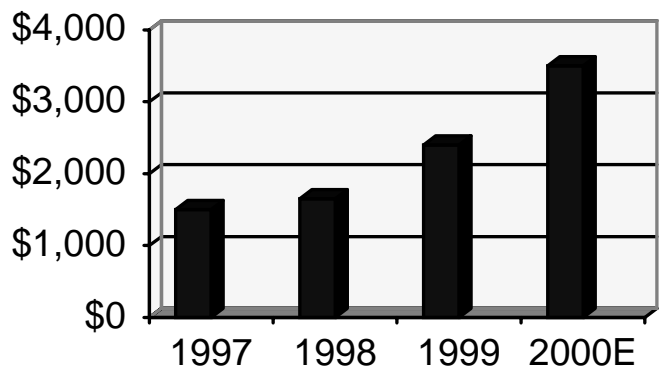

Figure 1. GaAs Revenue Forecast (CBIC World Markets)

GaAs Device Market 1999

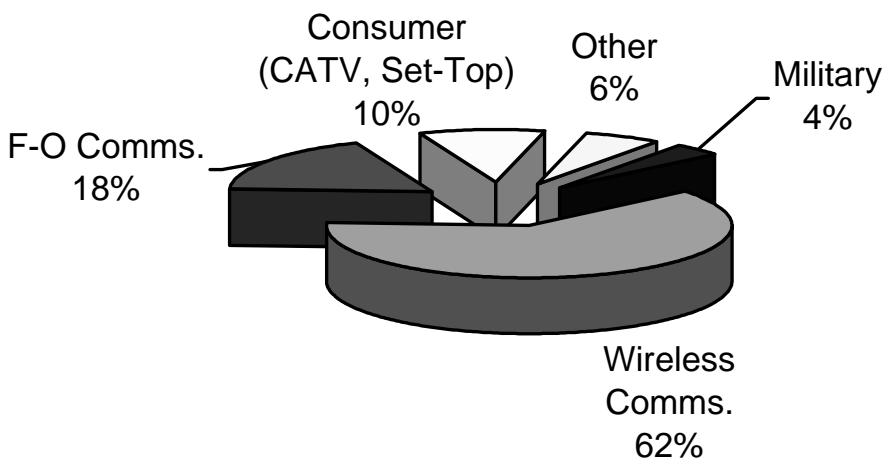

Figure 2 GaAs Semiconductor Market (CBIC World Markets)

\section{HIGH-VOLUME MANUFACTURING AT FILTRONIC}

In September 1999 Filtronic completed the purchase of a fabrication plant in the North East of the UK. The company embarked on an aggressive schedule to equip and implement a 6" pHEMT process with the intent to be operational in April 2000. The plan was completed on schedule and the first GaAs pHEMT wafer completed processing on $5^{\text {th }}$ April 2000. Over 100 production tools were installed within $4 \frac{1}{2}$ months and the entire Phase 1 start-up was completed within 8 months.

The plant has been converted from a silicon DRAM facility, which had previously manufactured 180,000 6" wafers per annum. The fabrication plant extends to over 310,000 square feet $(29,000$ square meters). There are over 100,000 square feet of clean rooms, with the main production clean room extending to over 54,000 square feet. The plant was originally configured for Class 10 operation

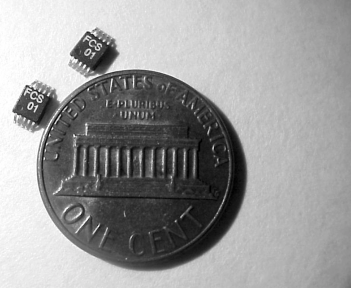

Figure 3 The first product from the 6" line - LNAs. 
(achieving up to Class 1 in some areas). Current requirements for GaAs have allowed greater economy of operation by changing to a combination of Class 100 and Class 1000 zones. The plant is well equipped to support un-interrupted high yield production, with a large high performance deionised water plant, generator station to cope with power fluctuations and large water storage facility. It is planned to ramp up production capacity over the next three years and it is estimated that the capacity by 2003 will be 50,000 6" wafers per annum. The ultimate annual capacity of the plant could be extended to over 175,000 such wafers.

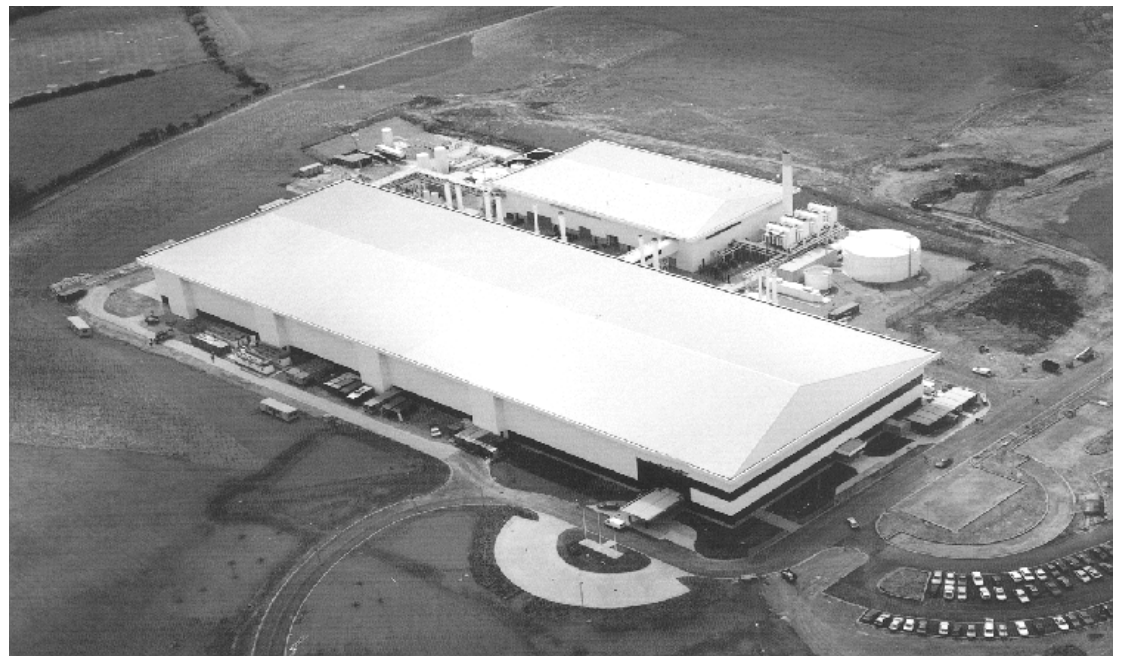

Figure 3. The Filtronic Compound Semiconductor Facility at Newton Aycliffe UK. Over 9,000 square meters of clean rooms with a 6" GaAs line.

\section{PROCESS TECHNOLOGY}

The material for production of pHEMT products for the 6" line is grown by MBE, with both internal and some external sourcing. State-of-the-art reactors are used to grow seven wafers at one time. Single and double heterojunction pHEMT structures are utilised for low noise and power applications respectively. Very high volume products use Nikon stepper defined $0.5 \mathrm{um}$ gates with electron-beam defined $0.25 \mathrm{um}$ gates available for moderate volume products. Discrete and MMIC product lines are available for both low noise and high power applications. MMIC lumped elements include tantalum nitride $(\mathrm{TaN})$ resistors, silicon nitride $(\mathrm{SiNx})$ capacitors and spiral inductors. Interconnects are provided by several metal layers: ohmic contact, gate metal, metal-1 and metal-2. Plated air-bridge technology is used for overpass connections and plated vias are used for ground connection. Plating technology is used to reduce processed wafer cost. Discrete devices use as little as seven front-side masking layers and MMICs use no more than ten (front-side layers with two backside layers). A combination of wet and dry etch techniques are used to optimise throughput and yield.

Development of enhancement mode (E-mode) pHEMT and HBT 6" technologies is underway to provide a full complement of device technologies. Separate R\&D and production facilities ensure that production is not hampered by development of new technologies. Duplication of equipment between facilities in the USA and UK ensures expedient technology transfer.

\section{AND RF TEST}

Volume test capability is catered for by a combination of Electroglas wafer probers and Agilent 4071 automated parametric testers for in line electrical process monitoring and end of line PCM 
check. This same equipment also allows for $100 \%$ DC electrical test of finished wafers. The Electroglas 4090micro film frame probers are capable of handling 12" (outside diameter) frames, supporting on tape the thinned finished 6" GaAs wafers. The same frames also allow die separation. Assembly of the dc yielding die, into small outline surface mount packages, is undertaken by a specialist off shore sub-contract assembly house. Final test at RF frequencies is catered for in house for medium volume production requirements and for engineering development. A specialist off shore sub-contract test house carries out very high volume production test. Agilent $84000 \mathrm{RF}$ testers are combined with packaged part handlers for $100 \%$ final test both in house and off shore. On-wafer RF PCM check has been utlized at the end of backside processing, for fast feedback of microwave performance.

\section{PROCESS DEVELOPMENT}

A methodology for process monitoring and process improvement has been developed to meet the demanding requirements for very high volume 6" GaAs wafer production with very high wafer yield from both front-side and backside processing. The approach is supported by TCAD using commercially available microwave CAD software together with physical device models for both "right first time design" and for a "process design for manufacturability" strategies. The TCAD models and physical understanding, in which virtual experiments can be implemented, is calibrated and overlaid by a practical Design of Experiments approach to (i) unit process development, (ii) process integration and (iii) characterisation of the process robustness. Finally the strategy is completed with a rapid parameter extraction function both to provide product performance feedback for the process development activity and to confirm the TCAD models.

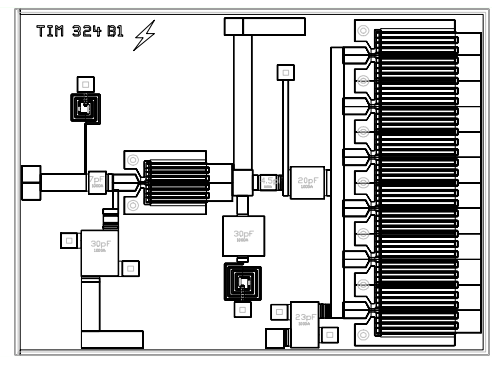

Figure 5 Prototype MMIC pHEMT handset power amplifiers.

\section{CONCLUSIONS}

A state-of-the-art very high volume GaAs fabrication facility and strategy have been described. The launch of an initial 6"pHEMT line has proceeded on schedule, producing a highly uniform process with very good results.

\section{ACKNOWLEDGEMENTS}

Many people have contributed to the success of this project. The author is grateful to the following for their ideas and contributions to this paper: Matthew O'Keefe, Nigel Cameron, Yi-Ching Pao, Richard Kerrigan, Steve Brozovich, Mike Bailey and John Atherton.

\section{REFERENCE}

1. S. Entwistle, "Trends in the Market for GaAs Devices", Compound Semiconductor, Vol. 6, No. 4, pp. 49-53May/June 2000 